\title{
Learning and Impact Assessment of Water and Access Projects on Community Health: La Garrucha, Guatemala
}

\author{
Michael Paddock, PE, PS \\ Senior Engineer \\ Engineers Without Borders-USA \\ Mukwonago, WI 53149 \\ Mike.Paddock@ewb-usa.org
}

\begin{abstract}
While many infrastructure projects fail, many succeed. Unfortunately, we seldom learn the important lessons to be gained from these successful projects because we fail to evaluate them many years after implementation. The study describes a 10-year postimplementation assessment of two Engineers Without Borders USA, Marquette University Chapter projects: 1) a vehicular bridge that enhances access to health care, education and markets; and 2) a potable water distribution system that provides clean water to 1300 community members. The community's primary goal for the program was to improve the health of its citizens, which they self-identified as "a crisis". The assessment reviewed the pre-implementation and ten-year post implementation data for infant mortality, maternal mortality and school absences due to water borne diseases. The results show dramatic improvements in all three areas with the infant mortality rate per 1000 births being reduced from 38 to 2; the maternal mortality rate per 1000 births being reduced from 15 to 0 and the school absences per month moving from 310 to 2 . The "best practices" of the program's implementation and 10-year review are documented to assist other organizations implementing similar programs.
\end{abstract}

Index Terms - access, bridge, Guatemala, health care, potable water.

\section{INTRODUCTION}

Access to health care facilities and safe drinking water were two key issues identified by the Guatemalan Highlands community of La Garrucha to address a self-identified health care concern.

The access to health care facilities and potable water are key methods to improve the overall health of a community. The United Nations Sustainable Development Goals (SDG's) include Goal \#3; Good Health and Well-Being and Goal \#6; Clean water and Sanitation, recognizing their importance to move the human condition forward. ${ }^{1}$ A lack of Water/Sanitation/Hygiene called WASH - especially in healthcare facilities has gone unrecognized until recently. A landmark report from the World Health Organization (WHO) and the University of North Carolina's Water Institute reviewed data from 129,000 facilities in 78 low to middle income countries, and found that healthcare facilities that are supposed to prevent and cure illnesses, instead leave staff at daily risk and patients contracting deadly infections they didn't have on arrival. $^{2}$ 
The study also found that fifty percent of healthcare facilities in low and middle income countries lack piped water, 33 percent of healthcare facilities lack basic toilets, and nearly 40 percent of healthcare facilities lack soap. The United Nations Secretary General himself made a global call to action for WASH in healthcare facilities and the WHO Director General joined in, "We can't expect \#HealthForAll without these essentials. We support the global call to action for WASH in ALL health care facilities." ${ }^{3}$

Many organizations conduct monitoring and evaluation studies on their programs within the first few years of implementation. This study by EWB-USA provides a rare ten-year post implementation review of the health changes experienced by the community after the implementation of EWB-USA's Marquette University program which constructed a vehicle bridge and potable water system.

Such studies are important, especially for infrastructure projects that are intended to last decades and may take years to fully impact the lives of the beneficiaries. Documenting the results, best practices and evaluation methods used after ten years will assist other organizations to implement other similar programs.

\section{BACKGROUND}

Achieving sustainable rural WASH services and accessing health care facilities continues to be a challenge in Guatemala. An analysis of water and sanitation coverage in the country done by the World Bank and based on SDGs 6.1 and 6.2 shows that only $12 \%$ of the Guatemala population has access to safely managed drinking water services, and only $15 \%$ to safely managed sanitation services. $^{4}$

The level of access to safely managed drinking water and sanitation services is unequal and strongly linked to inequality in the country. The rural population, which is mostly Mayan, has the lowest level of access to water and sanitation, and also the highest levels of poverty $-76 \%$ in 2014. ${ }^{5}$ This is especially pronounced in the Western Highlands of Guatemala, where the link between water and sanitation and health problems, is most clear. The Western Highlands have levels of chronic malnutrition linked to diarrheal disease among the highest in the world. In the department where this program is focused, $61 \%$ of children under five suffer from chronic malnutrition. Infant mortality, at 25 deaths per 1000 children, is higher than any country in the Western Hemisphere except Haiti and Bolivia. ${ }^{6}$ Access to health care facilities, education and markets is also a challenge with more than $70 \%$ of the rural poor in Guatemala needing to walk to such facilities. ${ }^{7}$ The Ministry of Agriculture has classified nearly the entire northern half of the country as having a low density of roads when weighted by population, while nearly the entire southern half has a medium to high road density. ${ }^{8}$

These inequalities have many historic roots. One of these, the 36-year civil war, still has special significance for the water and sanitation sector, despite ending 22 years ago. During that war, in which pro-government forces committed many massacres in the Western Highlands, leaving a strong distrust between the rural population and the government. That distrust has made it difficult for the government to build productive relationships with indigenous communities and effectively intervene in the sector. ${ }^{9}$ The other negative effects that low levels of access to water and sanitation have in Guatemalan communities are low levels of schooling and low quality of health care services. 
EWB-USA has implemented projects in Guatemala since 2004 and is a registered NonGovernment Organization (NGO) in the country. It has two offices in the Highlands region that supports over 60 projects per year, mainly led by EWB-USA university chapters. Longer term internships and fellowships (3-12 months) are also offered to students and professionals to support the Guatemalan staff which includes four Guatemalan registered engineers.

In 2004 EWB-USA Marquette University was contacted by Michael Shawcross, Director of the Guatemalan NGO P.A.V.A (Programa de Ayuda a los Vecinos del Altiplano, or Aid Program for Highland Communities) to assist with two solicitations.

One solicitation was for a vehicular bridge over the Rio Motagua and was signed by 14 communities. The stated objective was to provide access to health care, education and markets as the river was an impassable barrier for eight months each year. The river is nicknamed "The Assassin" due to the many people who have lost their lives trying to cross it.

The second was signed by the community of La Garrucha (also part of the first solicitation) who sought assistance in the design and implementation of a potable water system for its 1300 residents. The stated objective of the project was to address the self-identified health concern in which the previous five years had averaged:

- Infant mortality rate of $38 / 1000$ compared to the national average of 28.8

- Maternal mortality rate of $15 / 1000$ compared to the national average of $1.1^{10}$

- 310 absences at the elementary school each month due to diarrhea and/or parasites

A 70-foot cast in place concrete vehicular bridge was constructed in January 2005 which completed the transportation link using the local road network. The project included financial assistance from EWB USA Marquette Chapter, the Municipalities of Joyabaj and San Jose Poaquil with the 14 communities providing 60 volunteer laborers every day during construction. See Figure 1. 


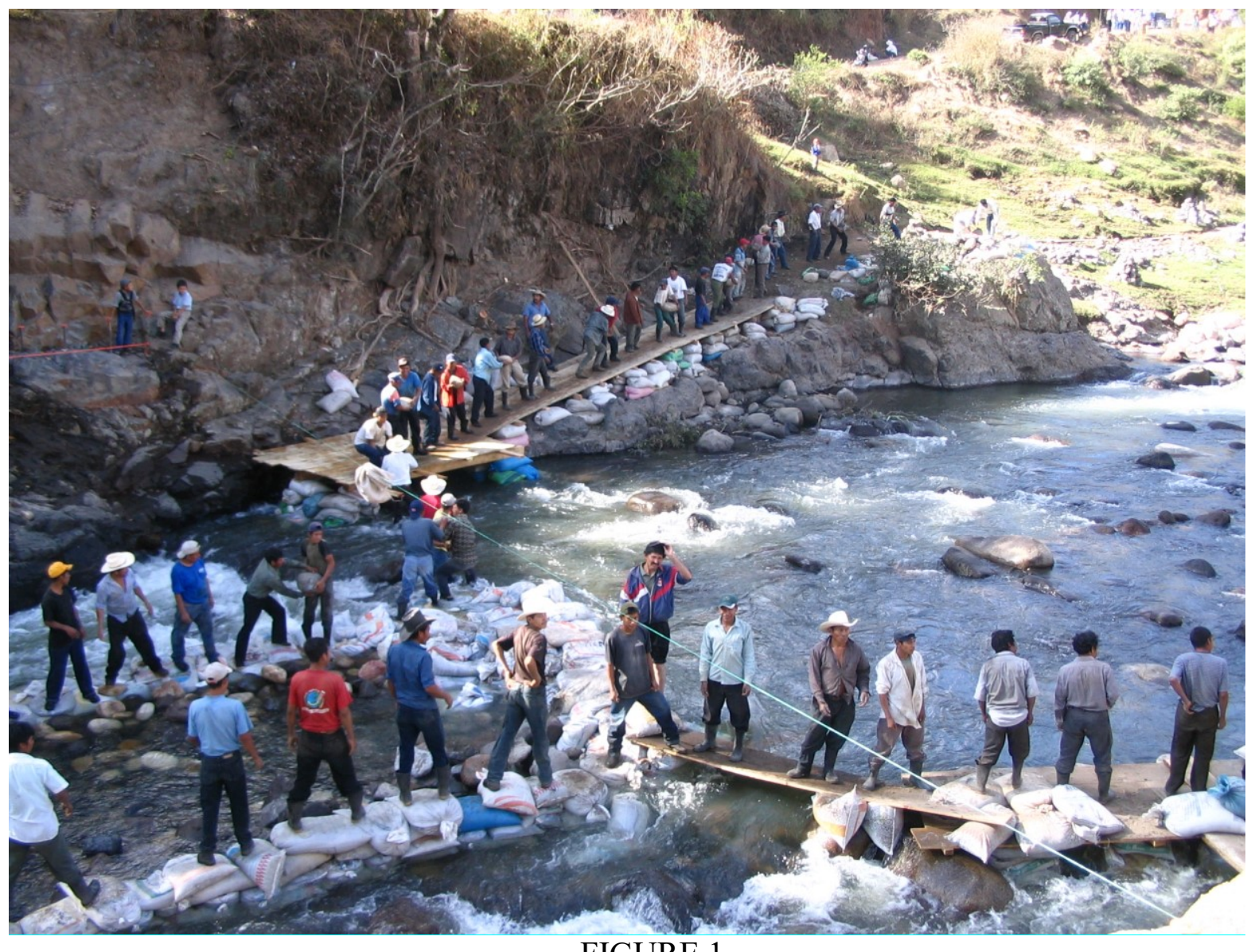

FIGURE 1

COMMUNITY VOLUNTEERS CONSTRUCTING TEMPORARY BRIDGE PIER.

A potable water system consisting of a spring catchment tank, six $\mathrm{km}$ conduction line and 22 $\mathrm{km}$ distribution system was completed in July 2008. See Figure 2. The project included financial assistance from the EWB-USA Marquette University Chapter, The EPA P3 program, the Municipality of San Jose Poaquil, the Guatemala National Government with the community of La Garrucha providing the labor during construction. 


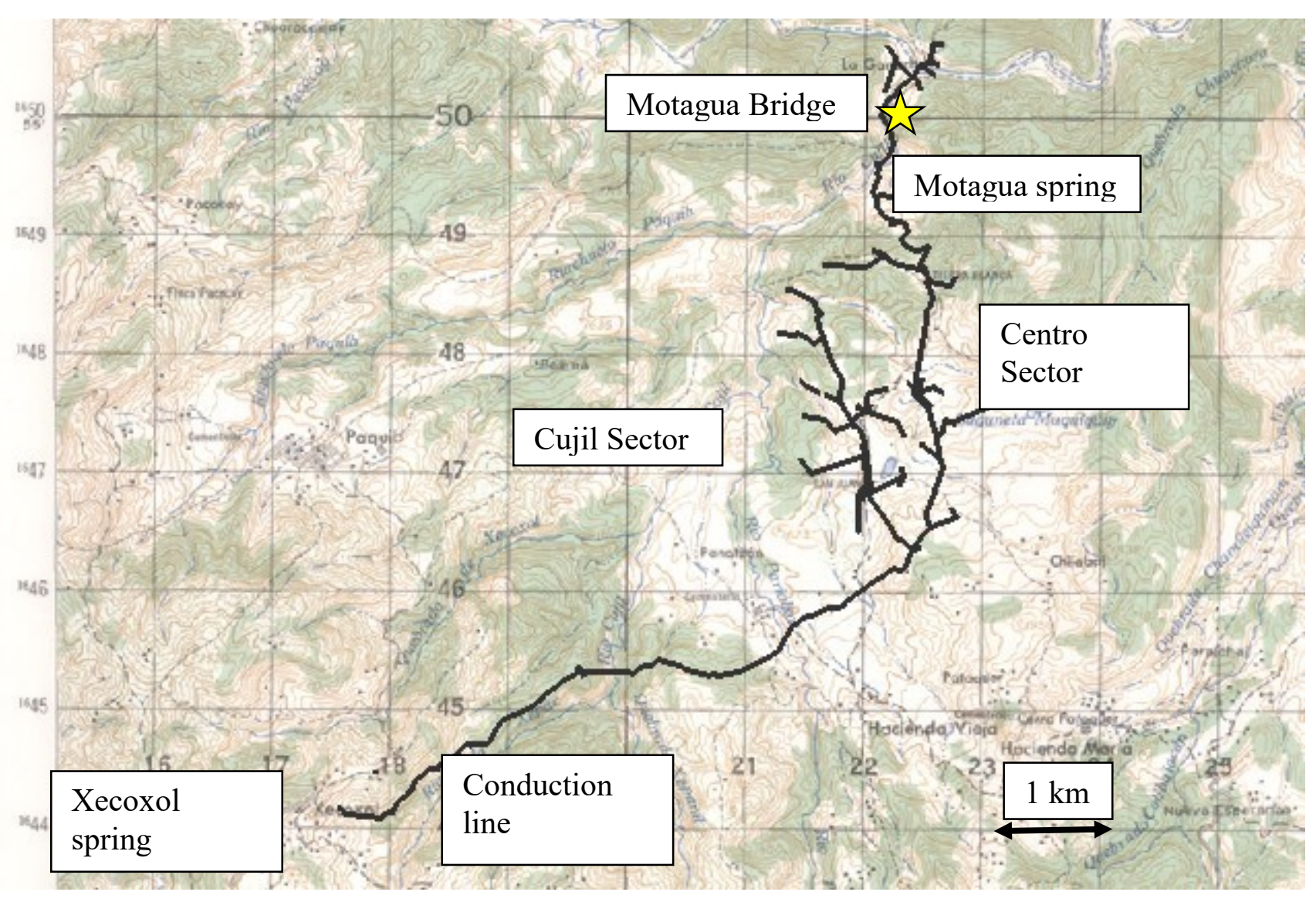

FIGURE 2

MAP OF LA GARRUCHA POTABLE WATER SYSTEM

Both projects were completed under the EWB-USA Marquette University program and were also part of the University's senior design or "Capstone" course. The student design team was mentored by a team of professional engineers from the EWB-USA Wisconsin Professional Partners Chapter.

During the construction of the water project, one of the members of the Marquette University design team worked as a fellow in country for three months supporting a Peace Corp Volunteer who was assigned to the community.

Over the next five years, Michael Shawcross continued to support the community with operation and maintenance advice for the potable water system. Coaching advice was provided for key activities such as:

- How to generate a water bill for its users

- How to address the situation when a resident is delinquent in paying their water bill

- How to collect the water fees and transparently account for the revenue and expenses

In June, 2010 Hurricane Agatha severely impacted the area causing damage to much of the infrastructure in the area and claimed several lives. The vehicle bridge was over topped when a landslide created a temporary dam that released a torrent when it broke. The vehicle bridge 
constructed by the community and EWB-USA was the only bridge over the Rio Motagua to withstand the event for its nearly $300 \mathrm{~km}$ reach to the sea, earning the name "The Unbeatable Bridge". The water system also sustained damage due to landslides including an aerial crossing over the Rio Cujil. All repairs were made and funded by the community except for an aerial crossing which received funding for a new crossing from Peace Lutheran Church in Wisconsin.

In January 2014 a five-year monitoring and evaluation study was conducted by EWB-USA and Michael Shawcross. No further assistance or coaching from EWB-USA or Michael Shawcross was provided after the study. In September 2018 a ten-year evaluation and impact review was conducted by EWB-USA to document the outcomes of the program.

\section{OBJECTIVES}

The objectives of this assessment were to:

- Determine the changes in the key health indicators of infant and maternal mortality as well as school absences due to water borne diseases (diarrhea and parasites).

- Determine if the community has been able to sustain the bridge and water projects for ten years, and if so, what best practices assisted in the sustainability of the project.

\section{METHODOLOGY}

The community received 48-hour notice prior to the assessment visit to ensure that non-typical improvements would not be made influencing the outcomes of the study. The ten-year assessment team consisted of:

- Jose Ordonez, EWB-USA Joyabaj Coordinator and Quiche Mayan speaker

- Fermin Ortega, EWB-USA Guatemala Construction Manager

- Cata Ixcol, EWB-USA Guatemala Women's specialist and Quiche Mayan speaker

- Michael Paddock, PE, PS. EWB-USA Senior Engineer

The team was hosted by the community with home stays, aiding in the collection of data and in understanding its results. The team was able to use the evenings to have informal discussions of the day's observations and findings, providing clarity to the information received. Members of the community's elected leaders accompanied the team during its activities that included:

- Visiting the source spring and collecting quality and quantity data

- Visiting the distribution tanks and collecting quality and quantity data

- Visiting 76\% (161 of 213) of the taps in service and conducting home interviews to determine the systems service level, measure the flows at the tap, and collecting information on the family's general health and latrine availability. If an adult was not present at the home, the data was not collected. This fact accounts for the $24 \%$ nonresponse rate.

- Interviewing the La Garrucha School director Abraham Cumes Simon and reviewing attendance information. Water, Sanitation and Hygiene (WASH) training sessions conducted by the school were also observed.

- Interviewing the La Garrucha clinic nurse, Efrain Chuta Luc and reviewing health care data. 
- Interviewing midwives Gavina Gomea and Josepha Morales who have been midwives for the community for 37 and 30 years respectively to gain their perspective on the changes they have experienced during their lifetimes. See Figure 3.

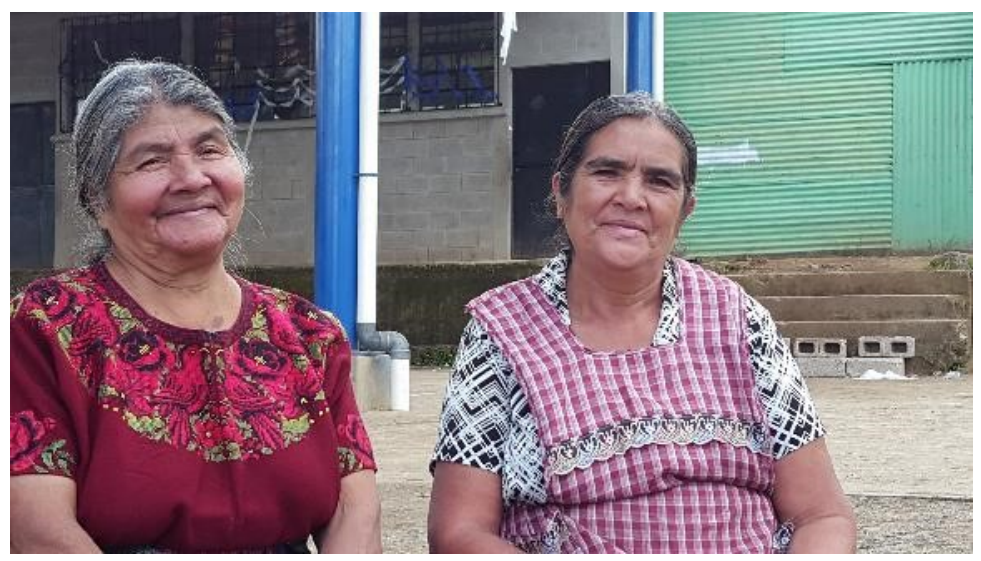

FIGURE 3

GAVINA GOMEA AND JOSEPHA MORALES, COMMUNITY HEALTH CARE PROVIDERS

\section{RESULTS}

\section{Impacts to infant and maternal health:}

Records were reviewed for the five-year period prior to the installation of the water system (2003 - 2008) and the ten-year period post installation (2009-2018). From 2009 - 2018, an average of 65 births occur within the community each year. Records for the exact number of births that occurred during the 2003-2008 timeframe were not available, hence 2003-2008 infant and maternal mortality rates are approximate using an assumed 65 births per year. See Table I.

TABLE I

INFANT AND MATERNAL MORTALITY

\begin{tabular}{|l|c|c|c|c|c|c|}
\hline Indicator & $\begin{array}{l}\mathbf{2 0 0 3 - 2 0 0 8} \\
\text { Mortalities } \\
\text { Iyearly } \\
\text { average] }\end{array}$ & $\begin{array}{l}\mathbf{2 0 0 3 - 2 0 0 8} \\
\text { mortality } \\
\text { rate / 1000 }\end{array}$ & $\begin{array}{l}\mathbf{2 0 0 8} \\
\text { Guatemala } \\
\text { national } \\
\text { mortality } \\
\text { rate / 1000 }\end{array}$ & $\begin{array}{l}\mathbf{2 0 0 9 - 2 0 1 8} \\
\text { Mortalities } \\
\text { [yearly } \\
\text { average] }\end{array}$ & $\begin{array}{l}\mathbf{2 0 0 9 - 2 0 1 8} \\
\text { mortality } \\
\text { rate } \\
\mathbf{1 0 0 0}\end{array}$ & $\begin{array}{l}\mathbf{2 0 1 7} \\
\text { Guatemala } \\
\text { National } \\
\text { mortality } \\
\text { rate per } \\
\mathbf{1 0 0 0}^{12}\end{array}$ \\
\hline $\begin{array}{l}\text { Infant } \\
\text { Mortality }\end{array}$ & $13[2.5]$ & 38 & 28.8 & $1[0.1]$ & 2 & 21.3 \\
\hline $\begin{array}{l}\text { Maternal } \\
\text { Mortality }\end{array}$ & $5[1.0]$ & 15 & 1.1 & $0[0]$ & 0 & 0.88 \\
\hline
\end{tabular}


Impacts to school absences:

The records were reviewed for the five-year period prior to the installation of the water system (2003 - 2008) and the ten-year period post installation (2009-2018). In 2018 there were 152 students registered in the school. See Table II.

TABLE II

SCHOOL ABSENTEEISM DUE TO DIARRHEA AND/OR PARASITES

\begin{tabular}{|l|c|c|}
\hline & $2003-2008$ & $2009-2018$ \\
\hline \# of absences per month due to diarrhea and/or parasites & 310 & 2 \\
\hline
\end{tabular}

Water system operations:

The water distribution system is divided into three sectors, Cujil, Centro and Motagua as summarized in Table III. See Figure 4.

TABLE III

WATER SYSTEM SECTOR SUMMARY

\begin{tabular}{|l|c|c|c|c|c|}
\hline \multicolumn{1}{|c|}{ Sector } & $\begin{array}{c}\text { Taps } \\
\text { in } \\
2008\end{array}$ & $\begin{array}{c}\text { Taps in 2018 } \\
\text { [\# of agriculture } \\
\text { taps] }\end{array}$ & $\begin{array}{c}\text { Annual } \\
\text { Growth Rate }\end{array}$ & $\begin{array}{c}\text { \# of taps visited during } \\
\text { assessment in 2018 } \\
\text { [agricultural taps] }\end{array}$ & $\begin{array}{c}\text { \# of taps not } \\
\text { functioning at } \\
\text { time of visit }\end{array}$ \\
\hline Cujil & 87 & $99[26]$ & $1.2 \%$ & $72[26]$ & 1 \\
\hline Centro & 51 & $93[13]$ & $6.1 \%$ & $68[13]$ & 2 \\
\hline Motagua & 19 & $21[1]$ & $1 \%$ & $21[1]$ & 0 \\
\hline Total & $\mathbf{1 5 7}$ & $\mathbf{2 1 3}[\mathbf{4 0}]$ & $\mathbf{3 . 1 \%}$ & $\mathbf{1 6 1}[\mathbf{4 0}]$ & $\mathbf{3}$ \\
\hline
\end{tabular}

Notes:

Taps in 2008 were those installed by the EWB project

Taps in 2018 includes those installed by the EWB project and those added by the community Agricultural taps are taps used for agricultural purposes such as watering fruit trees or livestock. 
International Journal for Service Learning in Engineering, Humanitarian Engineering and Social Entrepreneurship Vol. 14, No. 3, Special Issue, pp. 14-28, Fall 2019

ISSN 1555-9033

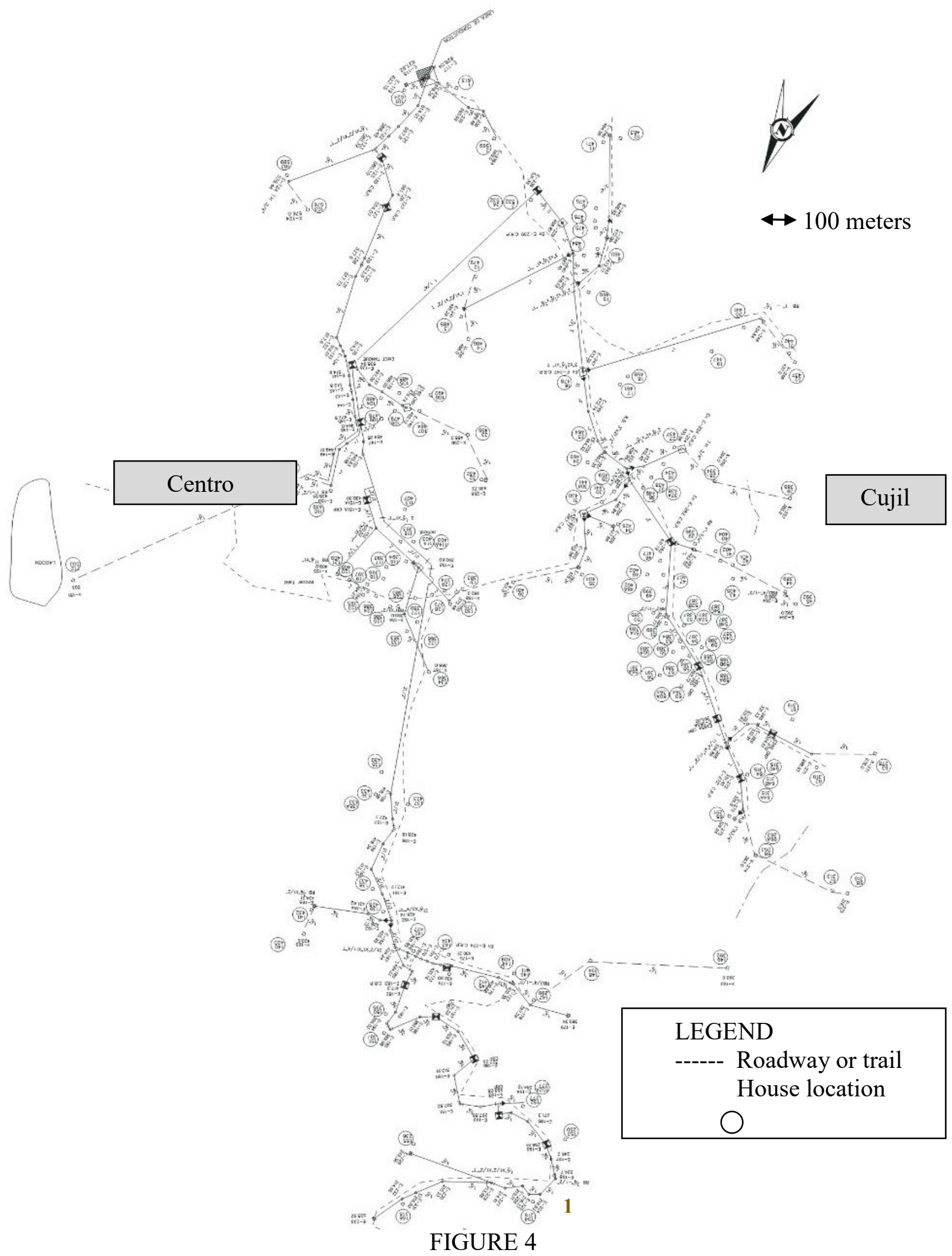

LA GARRUCHA POTABLE WATER DISTRIBUTION SYSTEM 
The system is clearly working well with only 3 of the 161 taps $(2 \%)$ visited during the assessment found to be non-functioning. It is noted that the 3 taps were repaired within 24 hours. The system is maintained by four plumbers. One for Cujil, one for Centro near the school, one for the Centro sector that begins near the Catholic church, named Tierra Blanca, and one for the Motagua sector. The plumbers are volunteers and rotate every year. To aid in the transition, the new volunteer works with the existing plumber for two months before the transition is complete.

A water committee was formed in 2017 to improve performance and provide transparency with the community users. It consists of the four plumbers and two other community members who are elected at large. The water committee charges 40Q (approximately \$5) per year and is responsible for collecting the fees. At the time of the study in September 2018, 17 of the 213 services have not paid for 2018. All 213 services paid the fee in 2017 and the water committee has not needed to turn off a service due to lack of payment for several years.

Since the construction of the potable water project, the municipality has made it illegal to turn off the water service to any residence. This has pushed the community to use volunteer plumbers, low annual fees and make a special fee requests when larger repairs are needed.

New connections are allowed if the families worked on the original system. A connection fee of $8,000 \mathrm{Q}(\$ 1,050)$ is charged for a new connection for a new family, but this has been very rare.

\section{Water usage:}

The spring sources and conduction line flows entering the distribution tanks were measured to check for pipe losses or leaks within the conduction portion of the system. All sectors measured the same flow at the distribution tank as at the spring source, indicating no measurable losses and a well-maintained system for its age of 10 years.

The distribution tank flows were then divided by the number of people within that sector to determine the quantity of water used per person per day. See Table V. It is noted that the distribution tanks were not overtopping indicating that the community was using all the water supplied. The residents generally indicated that they had consistent water supply during the rainy season but experienced periods of limited service during the dry season of the year.

\section{TABLE V}

WATER SYSTEM SECTOR WATER USAGE

\begin{tabular}{|c|c|c|c|}
\hline Sector & $\begin{array}{c}\text { Flow measured } \\
\text { at Distribution } \\
\text { tank }(1 / \mathrm{s})\end{array}$ & $\begin{array}{c}\text { Taps in 2018 } \\
\text { [\# of agriculture } \\
\text { taps] }\end{array}$ & $\begin{array}{c}\text { Usage (liters per } \\
\text { person per day) }\end{array}$ \\
\hline Cujil & 1.05 & $99[26]$ & 150 \\
\hline Centro & 1.05 & $93[13]$ & 160 \\
\hline Motagua & 0.3 & $21[1]$ & 200 \\
\hline Total & $\mathbf{2 . 4}$ & $\mathbf{2 1 3}[\mathbf{4 0}]$ & $\mathbf{1 6 0}$ \\
\hline
\end{tabular}


International Journal for Service Learning in Engineering, Humanitarian Engineering and Social Entrepreneurship Vol. 14, No. 3, Special Issue, pp. 14-28, Fall 2019

\section{Vehicle Bridge sustainability:}

The bridge was found to be in good condition and functioning well. The only access limitation described by the community was a lack of maintenance on the roadway by the Municipality of San Jose Poaquil, following severe rains.

The only major maintenance required was after Hurricane Agatha when the deck railing needed to be repaired. A full bridge inspection was done as part of the study and no defects or issues were identified. The community reported that the it's elected leaders typically inspects the bridge once a year at the beginning of the school year but have seldom needed to do any repairs. The concrete bridge has been painted approximately every three years for aesthetic purposes. See Figure 5.

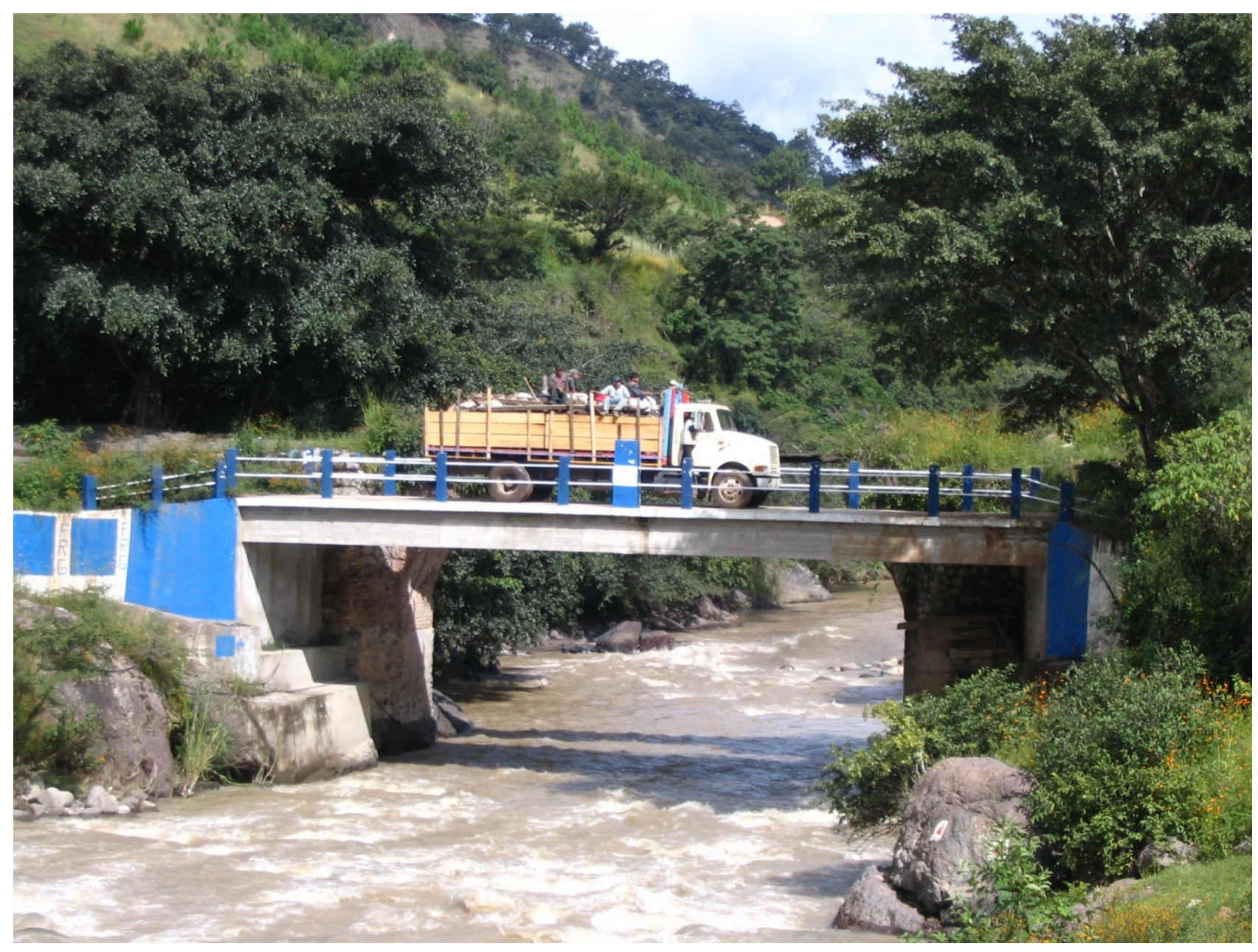

FIGURE 5

BRIDGE OVER THE RIO MOTAGUA 


\section{DISCUSSION}

The data shows a striking improvement in the community's health. The infant mortality rate per 1000 dropped from 38 to 2 and the maternal mortality rate per 1000 dropped from 15 to 0 . Absences at the school due to diarrhea and/or parasites have also been significantly reduced, going from 310 absences per month to 2 . The following factors were identified by the team and confirmed by the community for the improvement.

\section{Access to safe, potable water:}

The potable water system is well maintained and provides reliable service to the residents, school and health care facility. The health care facility tests the water for contamination twice a year (during the rainy season and dry season) to independently monitor water quality. Distribution tanks are cleaned monthly by the water committee with chlorine provided by the clinic removing contamination from the tanks and distribution lines.

At the time of the project's completion, the Municipality was to provide a Rural Water Technician to assist the plumbers within the municipality in maintaining the potable water systems (similar to a circuit rider program). An election caused a change in municipal government leadership and resulted in the program not being implemented. In fact, the new leadership passed a law making it illegal to turn off the water service to any residence, making it difficult to implement a water fee structure that could support a paid maintenance staff. This has forced the community to adapt the fee structure to use a volunteer plumber resulting in low annual fees and subsequently seeking special donations to support larger repairs. Although this financial water utility model is weak, it does appear to be working for this community. The fact that previous volunteer plumbers are still residing within the community does provide some redundancy to the technical capacity needed.

\section{Access to the Regional Hospital:}

Prior to the construction of the bridge and the roadway improvements, women gave birth in their homes with the assistance of a mid-wife. The midwives are trained to identify problem births during pregnancy, but access to a hospital was almost impossible. The bridge now allows for safe transportation to the Regional Hospital in Joyabaj where more advanced medical care is available.

\section{An integrated health care team:}

With the completion of the potable water system, the Ministry of Health staffed the clinic with a full time professional, Efrain Chuta Luc. His first mission was to build a health care team with the current midwives based upon mutual respect. It should be noted that the midwives provide general health care to the community along with assisting with pregnancies and birthing. Currently, training is provided twice a month and the sessions alternate between education of Western Medicine techniques and traditional Mayan medicine. The midwives feel they are well respected and a valuable part of the community health care team.

With the assistance and advocacy of Mr. Luc, midwives are now allowed to assist in the Joyabaj Regional Hospital birthing room. This has resulted in the midwives encouraging their 
clients to go to the Joyabaj Regional Hospital to give birth and nearly two thirds of all births now occur in the Joyabaj Regional Hospital.

\section{Midwives who reinforce good WASH practices:}

The midwives are on the front line of the community's health care and take pride in reinforcing good WASH practices during their home visits. This includes:

- Latrine inspection and instruction on proper use. It should be noted that of the 161 homes visited, 14 were identified as not having a proper, functioning latrine (9\%). Information for the number of functioning latrines in 2008 was not available, but reported by the Community's Water Committee as being two thirds without a proper latrine (67\%), showing a dramatic improvement.

- Proper storage of water and cleaning of the home's pila (a large volume sink for temporary storage).

- Encouraging the restriction of animals from entering the home.

- Proper hand washing techniques

- Proper food storage techniques to prevent vectors (primarily flies) from contaminating the food.

\section{The Formation of a Community Health Committee:}

To fully engage the community in its health, a Community Health Committee was formed by the community consisting of the clinic nurse, midwives and five elected members of the public. The Committee's responsibilities include:

- Identifying and helping the most vulnerable in the communities who may have health challenges

- Convincing expecting mothers to travel to the Joyabaj Regional Hospital when an atrisk pregnancy has been identified.

- Arranging for transportation for community members to the Joyabaj Regional Hospital when needed via community vehicles or ambulance.

\section{Other Observations:}

The amount of water provided to the community (160 liters per person per day) is nearly double the minimum amount recommended by the Guatemalan Ministry of Health ( 80 liters per person per day) for people. ${ }^{13}$ As a gravity fed system, the amount of water provided at the time of construction was in anticipation of a 20 -year life and an annual growth rate of $3 \%$. This resulted in a generous amount of water being provided at the time the construction was completed in anticipation of the community's growth. The community chose to not waste the water and used the water for other purposes including watering gardens and raising farm animals, mainly cows and pigs. The community now worries that the system does not provide sufficient water during the height of the dry season when the demand of the gardens and animals are at the highest.

With time this will continue to stress the water supply of the system. This was explained to the community and several options were discussed.

- Restrict the use of the water from the system to people only. This is problematic as many homes have adapted to the economic benefits of the gardens and farm animals. 
- Supplement the system with an additional water source. The original feasibility study identified a lagoon that had sufficient water that would be acceptable for human consumption if treated with a slow sand filter. The slow sand filter was piloted and proved to be effective in providing potable water. The cost of adding this source to the system $(\$ 20,000)$ and its subsequent maintenance is being considered by the community.

- Install water meters on all the taps and charge the users based upon the amount of water used. This would encourage conservation of water and also ensure fairness in the system as those who use the most water would bear the most cost. The cost of installing meters ( $\$ 75$ per tap) and the operational change is being considered by the community. It should be noted that the installation of water meters is now a requirement of any new potable water project built by EWB-USA in Guatemala.

\section{SUMMARY AND CONCLUSIONS}

This study shows that a community can take ownership and change the overall health of its members with the assistance of an engineering service organization. Although it is difficult to assess the exact contribution of each of the factors, the overall impact is impressive, and the community is to be congratulated.

The community attributes the bridge and water projects as the "catalyst of change" where the impact was larger than the infrastructure itself. The infrastructure projects demonstrated to the community that they could indeed do things previously believed to be impossible, if they worked together. Examples of community led initiatives include the formation of the Community Health Committee, advocating for changes in the Joyabaj Regional Hospital and the addition of another elementary school in the northern region of the community. The projects also helped mend relationships with the Municipal Government and the community. The people of La Garrucha now feel like they are part of the Municipal Governance system and feel comfortable advocating for themselves to the Government for their needs.

\section{ACKNOWLEDGMENTS}

The author would like to acknowledge the Marquette University Bridge Design Team consisting of James Ritter, Mollie Bednarowski, Paul Silva, Andy Thorson. Also, the Marquette University Water Design Team consisting of Amy Mikus Anderson, Jack Berg, Mark Von Dollen, Adrianna Stanley and Alicia Dougherty. Also, former Peace Corp Members Adam Kralik and Katie Bovitz who were critical to the infrastructure implementation. 
International Journal for Service Learning in Engineering, Humanitarian Engineering and Social Entrepreneurship Vol. 14, No. 3, Special Issue, pp. 14-28, Fall 2019

ISSN 1555-9033

\section{REFERENCES}

${ }^{1}$ D. Griggs. 2013. "Sustainable development goals for people and the planet." Nature. 495: 305-307.

${ }^{2}$ R. Cronk and J. Bartram. 2018. "Environmental conditions in health care facilities in low-and middle-income countries: Coverage and inequalities." International Journal of Hygiene and Environmental Health. 221: 409422

${ }^{3}$ United Nations Secretary General, March 22, 2018. "Secretary-General's remarks at Launch of International Decade for Action 'Water for Sustainable Development'." https://www.un.org/sg/en/content/sg/statement/201803-22/secretary-generals-remarks-launch-international-decade-action-water.

${ }^{4} 2018$ "Diagnostico de Agua, Saneamiento e Higiene y su relacion con la Pobreza y Nutricion en Guatemala". 41.

52018 "Diagnostico de Aguia. Saneamiento e Higiene y su relacion con la Pobreza y Nutricion en Guatemala". 18

${ }^{6}$ 2018. "Diagnostico de Agua, Saneamiento e Higiene y su relacion con la Pobreza y Nutricion en Guatemala". 51

${ }^{7}$ Puri, Jyotsna. 2010. "Guatemala: A Transportation Strategy to Alleviate Poverty Approach and Concept Paper”. 4

8 J. Alwang, P. Siegel, and D. Wooddall-Gainey. 2005. "Latin America and Caribbean Region Sustainable Development Working Paper 21 Spatial Analysis of Rural Economic Growth Potential in Guatemala". 16.

${ }^{9}$ D. Rothenberg. 1997. "Memory of Silence. The Guatemala Truth Commission Report”. Xxvii.

${ }^{10}$ www.indexmundi.com, using CIA World Fact Book data.

${ }^{11}$ www.indexmundi.com, using CIA World Fact Book data.

${ }^{12}$ www.indexmundi.com, using CIA World Fact Book data.

13 2011. "Guia de normas sanitarias para el diseno de sistemas rurales de abastecimiento de agua para consume humano" 27-28. 